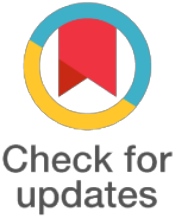

*For correspondence:

sandragumpil@yahoo.com

Competing interests: The authors declare that no competing interests exist.

Received: 2017-07-14 Accepted: 2017-08-05 Published: 2017-09-05

Copyright The Author(s) 2017. This article is published with open access by BioMedPress (BMP).

This article is distributed under the terms of the Creative Commons Attribution License (CC-BY 4.0) which permits any use, distribution, and reproduction in any medium, provided the original author(s) and the source are credited.

\section{Comparison between fresh and cryopreserved Human Amnion Mesenchymal Stem Cells (HAMCs) in terms of serial passaging, morphology and differentiation potential during long term culture}

\author{
Sandra Lisa Gumpil ${ }^{1}$, Kamaruzaman Ampon ${ }^{1}$, Helen Lasimbang ${ }^{2}$, Simat \\ Siti Fatimah ${ }^{1}$, S. Vijay Kumar ${ }^{1}$ \\ ${ }^{1}$ Biotechnology Research Institute \\ ${ }^{2}$ Department of Reproductive Health, Faculty of Medicine and Health Sciences, Universiti \\ Malaysia Sabah, Jalan UMS, 88400 Kota Kinabalu Sabah, Malaysia.
}

\section{Abstract}

The therapeutic efficiency of Human Amnion Mesenchymal stem cells (HAMCs) is significantly promising. However, its sustainability in long term sub-cultivation has yet to be identified, especially post-cryopreservation. There are concerns whether stem cells which are cryopreserved will be able to retain its functions and differentiation potential efficiently. The aim of this study is to determine the effects of cryopreservation on the serial passaging, morphology and differentiation potential of HAMCs culture post-cryopreservation compared to fresh HAMCs culture. HAMCs was isolated through serial enzymatic digestion of the amnion membrane of human term placenta after delivery. Fresh HAMCs cultures were sub-cultivated until passage 15 while cryopreserved HAMCs samples was preserved at passage 2 of the cell culture and revived after 3 months of cryopreservation period. Through microscopic observation, the cryopreserved HAMCs started to flatten and become larger in size, losing it fibroblastic feature as early as passage 6 . The enlarged and flatten morphological features of the HAMCs indicate that the cells began to lose its proliferative activity at this point. In comparison, the HAMCs normally began to enlarge when reaching passage 15 in non-cryopreserved HAMCs cultures. Fresh HAMCs cultures were able to be sustained up to 15 passages while cryopreserved HAMCs were not able to survive pass 10 passages of cell culture. Furthermore, it was observed that both fresh and cryopreserved HAMCs were able to retain its differentiation potential through osteogenesis and adipogenesis medium induction. This was experimentally visualized through positive staining of the calcium composite and lipid droplet in the induced HAMCs culture using Von Kossa stain solution and Oil Red-O stain solution, respectively. Despite retaining it differentiation potential, cryopreserved HAMCs were only able to survive a few passages after being revived. The result suggests that fresh HAMCs is a more suitable candidate to be used in cellular therapy and various clinical application as it were able to retain all its function in long term culture. 


\section{Keywords}

Human amnion mesenchymal stem cells; cell morphology; differentiation potential; long term culture; cryopreservation

\section{Funding}

Fundamental Research Grant Scheme (FRGS): FRG0359-SKK-2/2013

\section{References}

